University for Business and Technology in Kosovo

UBT Knowledge Center

UBT International Conference

2014 UBT International Conference

Nov 8th, 2:30 PM - 2:45 PM

\title{
Mechatronics in electrical efficiency and environmental impact
}

Sherif Hyseni

University for Business and Technology, sherifhyseni@gmail.com

Follow this and additional works at: https://knowledgecenter.ubt-uni.net/conference

Part of the Computer Sciences Commons, and the Engineering Commons

\section{Recommended Citation}

Hyseni, Sherif, "Mechatronics in electrical efficiency and environmental impact" (2014). UBT International Conference. 66.

https://knowledgecenter.ubt-uni.net/conference/2014/all-events/66

This Event is brought to you for free and open access by the Publication and Journals at UBT Knowledge Center. It has been accepted for inclusion in UBT International Conference by an authorized administrator of UBT Knowledge Center. For more information, please contact knowledge.center@ubt-uni.net. 


\title{
Mechatronics in electrical efficiency and environmental impact
}

\author{
Sherif Hyseni ${ }^{1}$ \\ ${ }^{1}$ University for Business and Technology, Master in Mechatronics Management \\ Prishtin, Kosovo \\ sherifhyseni@gmail.com
}

\begin{abstract}
This paper focuses on the mechatronic technology development, and its influent on electrical efficiency with a direct result in cost and environment. Considering the well-known European Union standard "20-20-20" and the possibility and responsibility of Kosovo in this field, the role of energy efficiency has great impact for future directions. This paper refers to a new technology solution for heating that is available on the local market, called "DAIKIN" by analyzing the functionality of this device and its promise to save up to $40 \%$ of the heating costs. Implementation of "DAIKIN" technology in state institutions in Prishtina, and also the simulation of the electrical efficiency and the cost and environmental results have been studied.
\end{abstract}

Keywords: Energy, Efficiency, Consumption, Environment

\section{Introduction - Actual energy and transport system}

Approximately $80 \%$ of the actual energy consumption comes from non-renewable energy sources and is used mostly for transportation and electricity. Around $3 / 4$ of the electricity production goes to buildings and only $1 / 4$ goes to production factories. This is the same also for fuel production $3 / 4$ of the overall production is used for transportation purposes and only $1 / 4$ is used for production factories.All over the world we have over 50'000 coal power plants, over 450 nuclear power plant, around 122 natural gas power plant, over 1.015 billion motor vehicles are in use in the world, around 450'000 airplanes and helicopters for civilian and military exists in the world.According what's mentioned above the biggest energy source in the world until now for creating electrical power is coal but the waste and the pollution that is created during that process for one (1) GW a year is equal to 8 million ton $\mathrm{CO} 2$ emission in the atmosphere. A proved example tells us that 1 car emits 4 tons $\mathrm{CO} 2$ /yare. And calculating all cars of the world gives a result that cars represent $40 \%$ of the world's $\mathrm{CO} 2$ emissions. This tow parts together are responsible for the global warming and are the starting points where we have to make big changes.

\section{Kosovo vs 20/20/20 - EU standard}

Since they have been warned of the possible risks that the planet earth may have in the near future, and considering the huge opportunity that offers the renewable energy systems, the European Union has defined its targets and their member states for 2020. These targets, known as the "20-20-20" targets, they set three key objectives for 2020 and they are:

- $20 \%$ more renewables in the final consumption of electricity,

- $20 \%$ more energy efficiency and

- $20 \%$ reduction in EU greenhouse gas emissions from the level of 1990

And an astonishing fact is that the most states in the EU already achieved this target but they do not stop and be satisfied with their achievements they continue investing in this growing industry because of the economic benefits and the new job opportunity and the moral issue regarding to the health of our planet and of course for the living creatures that live on this planet.

\subsection{Kosovo capacity and duty towards global problems}

Kosovo is one of the newest countries in the world recognized by 108 states. Coming after a war in the year 1998-1999 and until wining the independence on February 17, 2008 Kosovo goes through many 
different problems. Also the actual political end economical potential of Kosovo is not very stable and in this condition we cannot do much to help on global problems.

But considering that energy efficiency is a contribute and is part of the solutions needed to overcome the risk of global warming. And not to forget that during the war in Kosovo nearly everything was burned to the ground, therefore we need to invest with new technologies that have already high efficiency solutions integrated. And updating old machinery or old technology with new technology can be very proactive in at least one of the EU targets that are to be achieved until 2020 we must increase the electrical efficiency by $20 \%$.

\section{Kosovo's Energy system}

Nearly $100 \%$ of electricity generated in Kosovo is coming from Coal power plants. Energy generation division is separated in two power plants "Kosova A" and "Kosova B" and chemical separations that are lied in the around area of Kastriot that is about $8 \mathrm{~km}$ far from Prishtina capital city of Republic of Kosovo. The total electricity production capacity of these two power plants is $5160 \mathrm{GWh}$.

\subsection{Power plant "Kosova A"}

Power Plant "Kosova A" is composed from five generation units known as A1, A2, A3, A4 and A5. Unit A1 of this power plant is set in operation by the year 1962 with generation capacity of $65 \mathrm{MW}$; A2 by 1965 with generation capacity 125MW; A3 by 1970 by generation capacity of $200 \mathrm{MW}$; A4 by 1971 with generation capacity of $200 \mathrm{MW}$ and A5 by 1975 with generation capacity of $210 \mathrm{MW}$. Units A3, A4 and A5 are still in function. According actual plan there are in use two units while third one is the "hot" reserve because of their low readiness that is because of its seniority. Units A1 and A2 are out of operation without defined status and according actual plans this will stay like that till the end when is planned to be done its decommissioning together with other units.

Quantity of generated energy from PP "Kosova A" per year is $1500 \mathrm{GWh}$.

\subsection{Power plant "Kosova B"}

Power Plant "Kosova B" is composed by two generation units as there are B1 and B2. First unit B1 was set in operation by the year 1983 with generation capacity of 340MW, while second unit (B2) by 1984 with generation capacity of $339 \mathrm{MW}$. Both units are in generation and are in good condition. Based on finished investment and following investments there was improved evidently units situation that even these ate old about 25 years abovementioned units ate in high technical readiness. 2008 and 2009 are years when was achieved maximum generation in both units during its history since units were set in operation by the year 1984 .

Quantity of generated energy from PP "Kosova B" per year is 3650GWh.

\section{Electricity usages in our home's}

It is mention that $3 / 4$ of the electricity production goes to buildings. But for what it is used, $60 \%$ of the electricity in our homes is used for heating and cooling purpose, another $12 \%$ is used for hot water and the rest $28 \%$ is used for other household devices. There are different methods and solution offer for heating, cooling and in our days it includes also the solution for hot water that's equal to the $72 \%$ of the electricity use in our buildings. The most known and used solutions regarding this issue in Kosovo for heating is using:

- Wood 
- Wood Pellets

- Coal

- Oil

- Geothermal

- Solar

- Air

What have this solution in common and which one is the best and most environmental friendly to use All of them uses in one way or another electricity, mostly for water pump. But they can be divided in two groups, first group is consisting of the solution that use fossil fuel like: wood, wood pellets, col, oil and the second group that use renewable energy sources like: geothermal, solar and air. The aim is to minimize the use of fossil fuel because of the pollution that they create. For this reason there are only three remaining alternative left form the second group.

Heating using geothermal method is a good solution for small houses with garden, not a very good solution for high buildings without garden.

Solar, is also a very good solution but the usual problem in this field is the sun and the availability during 24 hours.

Air, sounds promising, it is everywhere and has a heating capacity also in temperature $-25^{\circ} \mathrm{C}$.

\section{Air heating solution - "DAIKIN"}

Daikin is the world's largest manufacturer of energy-efficient heating, cooling and ventilation products and systems that provide outstanding indoor comfort control for homes, businesses and industrial customers. Daikin offers several products with different capacities depending on the volume and the capacity required for heating a specific area. Mostly Daikin offers two units for heating and cooling one outside unit and one inside unit that of course have different function. The outside unit consists of four main parts: ventilator, evaporator, compressor, water pump - between the units. And the inside unit consists of three main parts: condenser, water pump - to heating body (floor heating etc.) and one expansion wave.

For realizing the heating or the cooling Daikin uses a refrigerator fluid called Freon-R410A that flows between the units and due some processes it goes from the liquid form to a gas form, where it changes also the parameters of the heating capacity. In the following picture is described the heating system used from Daikin

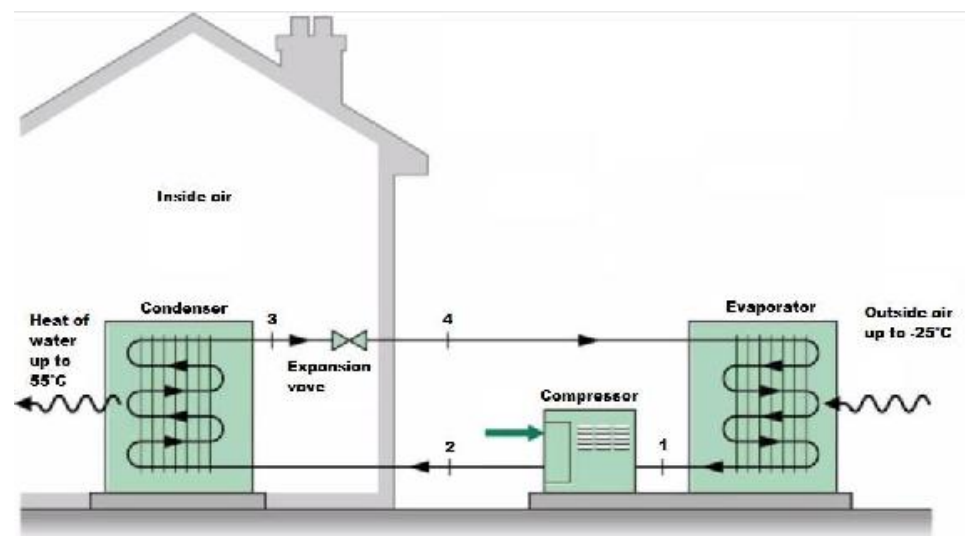

Fig. 2. Heating process using Daikin solution 
In the image above is described the process of heating. Starting by the outside unit where the ventilator is mounted. His role is to get the as much air as possible in the evaporator. In this part the air is used to prepare the fluid Freon-R410A that is in a liquid form to a common temperature, before it flows to the third part that would be the compressor. The air has a heating capacity in up to $-25^{\circ} \mathrm{C}$. Therefore in the 1 st step the fluid has approximately a temperature up to $10^{\circ} \mathrm{C}$. Than it goes to the compressor where the fluid will be compressed and by compressing this fluid we have in the 2 nd step a temperature up to $70^{\circ} \mathrm{C}$ with a pressure up to 28 bars, this brings the fluid to another form from liquid to gas. And through the water pump it flows to the inside unit.

In the inside unit the fluid flows through the condenser that is full with water and it releases his temperature to the water that gets a temperature up to $55^{\circ} \mathrm{C}$. Through another water pump the water will go to the heating bodies inside the building that can be for example floor heating. So by releasing his temperature the fluid become colder and in the $3 \mathrm{rd}$ step the temperature is again up to $10^{\circ} \mathrm{C}$. For completing the flow cycle the fluid has to go through an expansion wave. So that in the 4 th step the fluid has to become colder than the outside temperature and due to this it also again changes his form, now from gas to liquid. In this step the temperature difference between the fluid and the outside temperature should be as higher as possible to have a greater heating effect.

This process continues after and after again and the good side of this is that in summer time it can be used for cooling the building by inversing the steps.

\section{Case study of implementing "Daikin" technology in state buildings in Prishtina}

In this case study first is analyzed the energy consumption of the state buildings in Prishtina in the year 2013. By getting three indicators:

- The amount of money that the municipality of Prishtina pays for electricity.

- The electricity power that is needed to fulfill the consumption requirements of the municipality of Prishtina.

- The environmental impact of producing that electrical power in Kosovo.

The total number of state buildings in Prishtina is 206. Prishtina has:

- Specific schools 1

- Kindergarten 53

- Primary schools 66

- High schools 17

- Family medicine center 28

- Other buildings 41

The total energy consumption of this buildings is equal to $768,402.49 €$, that is equal to an electricity power of $6,558,573.66 \mathrm{~kW}$, and by producing this electricity Kosovo emits to the environment approximately 52.464 ton $\mathrm{CO} 2$ all this for one year.

The second aim of this case study was calculating the difference that would be if the municipality of Prishtina decide to implement Daikin technology in their buildings for heating and cooling, and for such buildings the saving ratio is equal to 3.9 .

In Table 1 are shown the results that may be obtained after the implementation of Daikin technology.

Table 1 Results of savings with Daikin Technology for heating and cooling. 


\begin{tabular}{|l|l|l|}
\hline Actual situation & $\begin{array}{l}\text { Savings after } \\
\text { implementation }\end{array}$ & Future situation \\
\hline $768,402.49 €$ & $196,021.04 €$ & $572,381.45 €$ \\
\hline $6,558,573.66 \mathrm{~kW}$ & $1,673,105.52 \mathrm{~kW}$ & $4,885,468.14 \mathrm{~kW}$ \\
\hline $\begin{array}{l}52.46 \text { ton } \mathrm{CO} 2 \\
\text { emitting }\end{array}$ & 13.38 ton $\mathrm{CO} 2$ emitting & 39.08 ton $\mathrm{CO} 2$ \\
\hline
\end{tabular}

\section{Conclusion}

The first results that we got by this case study are impressive, because there it is only calculated the electricity power savings, but future studies will include also the improvement of the actual heating systems used by this buildings, that for now are running by the use of fossil fuels that also have a bad emitting rate and a high influent on the air pollution. The results will even be more impressive if all state buildings in Kosovo would implement this new technology. That would be a step closer to the target of $20 \%$ efficiency until the year 2020 .

Not to forget also recommending the use of household devices with the highest efficiency mark in our homes because a little by a little can become enough to be part of global problem solution.

\section{References}

1. http://www.kek-energy.com/gjenerimi.asp - last visit: 03.11 .2014

2. http://www.kek-energy.com/doc/Gjendja\%20mjedisore $\% 20$ ne $\% 20 \mathrm{KEK} \% 20$ per $\% 20 \mathrm{vitin} \% 202013$.pdf last visit: 03.11.2014

3. http://www.kekenergy.com/doc/KEK\%20Analysis\%20and\%20Commentary\%20on\%20Sierra\%20Club\%20Reports\%20Alb.p df - last visit: 03.11.2014

4. http://www.institutigap.org/documents/2305_CmimiEnergjiseELektrike.pdf - last visit: 03.11.2014

5. http://www.tsp-data-portal.org/Breakdown-of-Electricity-Generation-by-Energy-Source\#tspQvChart - last visit: 03.11.2014

6. http://www.youtube.com/watch?v=23-5v9KRAX4 - last visit: 03.11.2014 